\title{
L'impact du Printemps arabe sur le Sahel
}

\author{
Olivier Hanne
}

\begin{abstract}
Agrégé et docteur en histoire, chercheur-associé à l'université d'Aix-Marseille et aux Écoles de SaintCyr Coëtquidan, auteur de L'État islamique, anatomie du nouveau Califat, BG Éditions, 2014. Il a aussi dirigé l'ouvrage Mali, une paix à gagner. Analyses et témoignages sur l'opération Serval, Lavauzelle, 2014.
\end{abstract}

$\mathrm{L}$ e danger djihadiste s'est rapidement accéléré en 2014. La fulgurante avancée de l'État islamique en Syrie et en Irak s'est accompagnée, 4000 kilomètres plus loin, d'une déstabilisation croissante des régions sahéliennes, dans un contexte géographique pourtant radicalement différent. Un retour rapide sur les cinquante dernières années peut permettre d'identifier les causes internes et externes qui ont brutalement accru les tensions politiques et religieuses au Sahel.

\section{Un Sahel instable depuis l'indépendance}

La précarité sahélienne est frappante dès l'obtention des indépendances. Les rébellions et les coups d'États militaires empêchent la construction de nations démocratiques tout comme la fracture ethnico-religieuse partageant les peuples nomades musulmans des peuples sédentaires, chrétiens ou animistes. Depuis la guerre du Biafra en 1967 au Nigeria, sans compter les réclamations touaregs, les pays du Sahel ne connurent pas une seule année de stabilité, d'autant que les difficiles conditions économiques ne permettaient pas de payer la paix sociale.

L'islam, pourtant commun à la plupart des populations sahéliennes, ne représenta jamais un facteur d'unité et de pacification. La pratique religieuse s'accompagne d'une certaine tolérance, contrairement au salafisme arabe. Ici, on écoute à la fois le prêche du vendredi, les poésies traditionnelles des griots et on pratique avec les marabouts une magie médicinale mêlée d'animisme.

Pourtant, l'islam africain ne rejette pas les pratiques du djihâd, puisque dans la seconde moitié du XIX ${ }^{\mathrm{e}}$ siècle une multitude de petits États djihadistes tentèrent de résister à la pénétration européenne (djihâd de Samori ou d'al-Hadj Omar Tall). À partir du XVIII ${ }^{\mathrm{e}}$ siècle et jusqu'au $\mathrm{XX}^{\mathrm{e}}$ siècle, apparurent dans le Sahel les confréries, des associations religieuses élitistes proposant un chemin particulier (une tarîqa), une méthode pour vivre un islam initiatique et une forme de vie mystique et de renoncement. De multiples confréries avec leurs centres 
d'études se diffusèrent dans toute l'Afrique noire (la Tidjâniyya parmi les plus connues), structurées dans l'obéissance à un maître (un chaykh), vénéré par ses disciples, même après sa mort.

Avec les années 1950-1960, des courants réformateurs intégristes et puritains pénétrèrent dans la jeunesse africaine. Les étudiants partis au Caire ou en Algérie revinrent avec les principes d'un islamisme politique et juridique, dénonçant l'animisme, les marabouts, les pratiques des confréries et militant pour une éducation islamique populaire. C'est sous leur influence que certains États choisirent la sharia comme source de leur droit (Mauritanie, Nord du Nigeria, Soudan, Somalie). Le wahhabisme, porté par l'argent du pétrole saoudien, rencontra un succès grandissant auprès de pieux chaykhs locaux, jusqu'à concurrencer les vieilles confréries, jugées dépassées. Le salafisme fut aussi soutenu par les capitaux libyens du colonel Kadhafi, pourtant considéré comme un hérétique par les oulémas du monde arabe.

\section{Le renforcement de l'islamisme (années 1990-2010)}

Dans les années 1990, à la suite de la crise en Algérie, de l'influence des réformateurs salafistes et de la situation climatique et économique dramatique du Sahel, les différents islams africains s'opposèrent de façon accrue.

Les prêches au Mali dénoncèrent pêle-mêle les marabouts, le soufisme élitiste, la sorcellerie, l'animisme, le tout englobé dans l'accusation de bida (" innovation condamnable »). On milita pour une éducation islamique, populaire, propice à la constitution de la Umma, la nation musulmane. Des associations inspirées des Frères musulmans égyptiens virent le jour au Niger, en Mauritanie, au Mali. L'ensemble de ces courants réformateurs nourrit les revendications des populations musulmanes déclassées, ainsi au Nord du Tchad et du Mali. Ici, l'État se révéla incapable d'encadrer le succès et l'influence du wahhabisme face aux formes traditionnelles de l'islam africain. Les sociétés sahéliennes adoptèrent les nouveaux critères du salafisme mondialisé (port du khéfié, tenue blanche saoudienne, hidjâb, niqab, pèlerinage, prédications djihadistes, solidarité palestinienne, rigorisme moral). Chérif Madani Haïdara, soutenu par la puissante association Ançar Dine (1991), l'un des prédicateurs maliens les plus écoutés, représente bien la synthèse de l'islam local depuis quarante ans, puisqu'il a à la fois le visage d'un fondamentaliste wahhabite et celle d'un saint soufi.

Le djihadisme international, inspiré de l'Afghanistan antisoviétique puis des taliban, apparut brutalement après 2003. La fin de la guerre civile en Algérie poussa les terroristes du Groupe islamique armé (GIA) à trouver refuge au Nord du Mali et en Mauritanie où ils fusionnèrent avec la branche locale d'Al-Qaïda pour former $A Q M I$ (Al-Qaïda au Maghreb islamique) en 2007, sous la direction de l'Algérien Abou Moussab Abdelwadoud. L'exaspération des Touaregs contre les gouvernements sahéliens poussa ces nomades à s'y rallier de façon opportuniste. Au même moment, au Nord du Nigeria, se constitua le groupe Boko Haram. Pour 
assurer leurs achats d'armes, ces groupes pratiquèrent le terrorisme, l'enlèvement et s'engagèrent dans les multiples trafics du vaste espace saharien (drogues, contrebande, migrants, armes). Mais cet islamisme violent et étranger à l'Afrique noire ne rencontra qu'une faible adhésion des populations, qui ne reconnaissaient ni ce djihadisme ni ses chefs, qui étaient tous Arabes. Les vieilles oppositions ethniques restaient vivaces. L'état de délabrement des institutions politiques et militaires au Sahel, et particulièrement au Mali, accéléra l'implantation djihadiste et donna les coudées franches aux rebelles touaregs, vrais maîtres du terrain.

\section{Les conséquences immédiates du Printemps arabe}

Les printemps arabes (2010-2012) ébranlèrent la Tunisie, l'Égypte et surtout la Libye dont les pouvoirs autoritaires luttaient contre l'islamisme. La chute de Kadhafi (octobre 2011) dispersa son arsenal militaire et ses mercenaires noirs dans toute l'Afrique, renforçant ainsi les djihadistes du Sahel et leur place dans les trafics sahariens. Bientôt accédèrent au pouvoir des partis islamistes qui avaient été persécutés par les dictateurs : Ennahda en Tunisie, Morsi et les Frères musulmans en Égypte. Au Maroc et en Algérie l'explosion des mécontentements fut évitée de justesse. Mais ces victoires inespérées du salafisme eurent pour effet de promouvoir dans le Sahel l'islamisme, désormais légitimé en Afrique du Nord par le suffrage universel et les révolutions populaires. Allait-on aussi en Afrique noire se débarrasser de ces régimes honnis, pro-Occidentaux et clientélistes ?

En quelques mois, de nouveaux groupes terroristes apparurent : le Mouvement pour l'unicité et le jihad en Afrique de l'Ouest (MUJAO) au NordMali, fondé par Ahmed Kheirou avec des Maliens, des Mauritaniens et des Nigériens ; Ançar el-Din, groupe salafiste touareg; Ançar al-Sharia, fondé par des dissidents libyens ; Les Signataires du Sang, ex-GIA algérien, fondé par Mokhtar Belmokhtar, responsable de l'attaque sur In Amenas en janvier 2013. Le fragile équilibre des islams africains fut rompu. Les milices se regroupèrent et nouèrent une alliance opportuniste avec le Mouvement national de libération de l'Azawâd (MNLA) touareg à tendance laïque. Début janvier 2012, cette nébuleuse hétéroclite fondit sur Leré et Niafundé. En février, Ménaka et Tinzawaten sont prises ; en mars, c'est le tour de Kidal, Tessalit et Gao. Le mois suivant, Tombouctou tombe! Les djihadistes instaurent un régime islamiste qui prône le salafisme pur et dur auquel certains prédicateurs ont habitué les populations depuis trente ans. On brise les mausolées des chaykhs des confréries, on brûle les manuscrits médiévaux qui touchent aux sciences non coraniques (mathématique, astronomie), on lapide, on ampute, on interdit le football. Bien que ces violences dépassent les exigences des salafistes maliens, plusieurs centaines de locaux rejoignent les rangs des combattants, les uns par convictions, les autres par appât du gain ou simplement en recherche de quelque chose à manger... L'ensemble du Nord-Mali devient l'Azawâd islamique indépendant. La panique gagne le Sud du pays et l'Europe, déjà inquiète de la situation au Maghreb et en Syrie. 


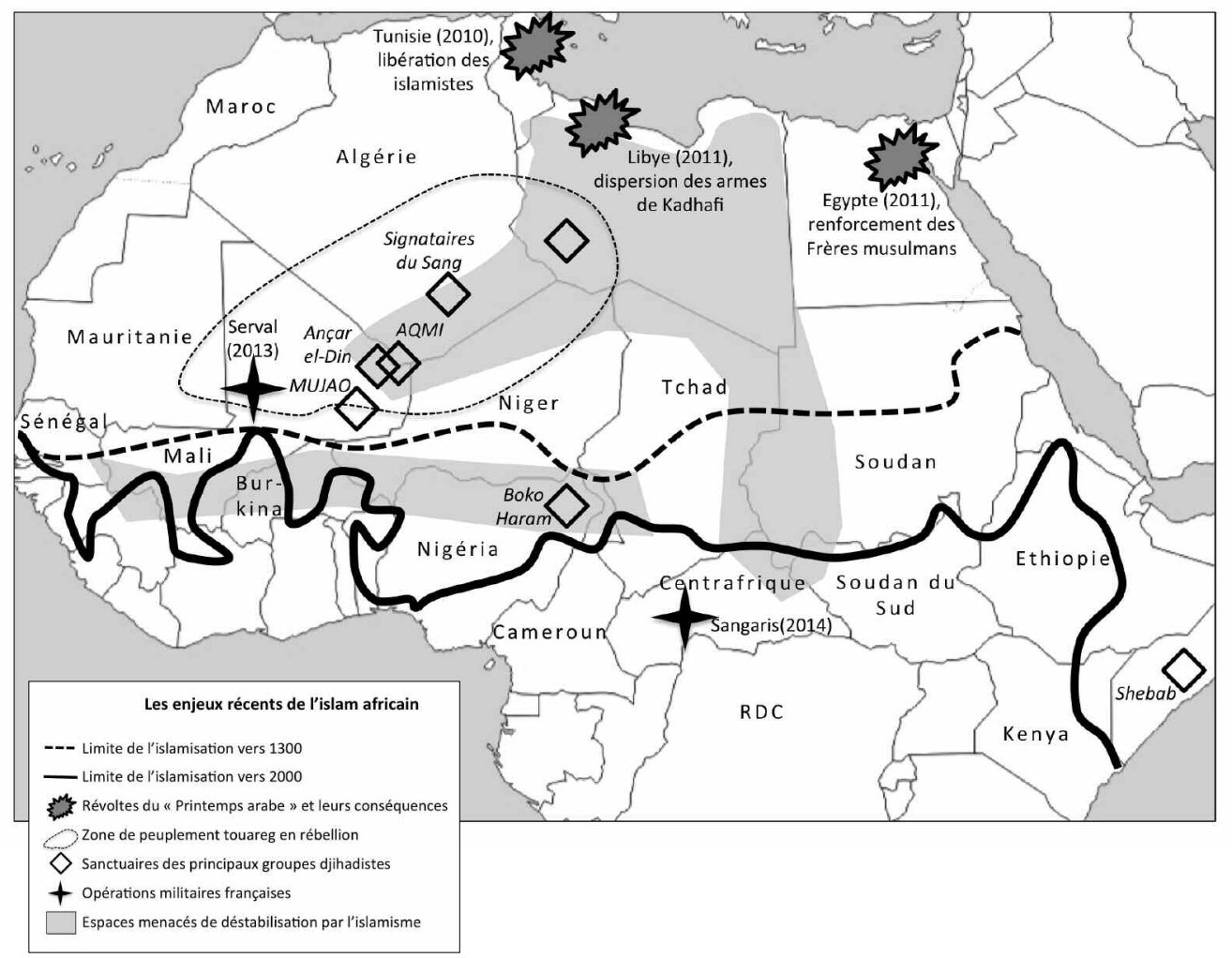

Bientôt, le récit des exactions islamistes fait le tour du monde. Cependant, l'alliance des groupes armés avec le MNLA s'effrite jusqu'à dégénérer en affrontements (juin-novembre 2012), tandis que les djihadistes lancent une opération sur Mopti (début janvier 2013). Le Sud est-il menacé ? L’expérience de terrain montre qu'en réalité la conquête du Mali méridional relevait de l'impossible. En effet, le Nord, peu peuplé, offre des conditions ethniques et religieuses propices à l'installation durable des djihadistes (identités arabo-berbères, salafisme implanté, alliance avec les Touaregs), contrairement au Sud, démographiquement plein, constitué d'ethnies subsahariennes, haïssant les Touaregs et dont l'islam est plus confrérique que salafiste. Le djihadisme n'aurait pas tenu ici sur le long terme.

La mouvance djihadiste sahélienne ne reflète d'ailleurs nullement un islam intégrateur, puisque, au contraire, un profond racisme parcourt ses rangs, héritage des mentalités esclavagistes : les chefs sont des Arabes blancs, les cadres des Touaregs, des Maures ou des Algériens noirs ; et les Maliens noirs des combattants mal logés et mal nourris. La conquête du Nord-Mali en 2012 par les différentes branches djihadistes fut, on le sait, mal accueillie par les populations en raison des exactions commises par ces « étrangers " à l'encontre de l'islam traditionnel. L'arrivée des troupes françaises ne provoqua donc pas contre "l'infidèle " le soulèvement attendu par les islamistes. 


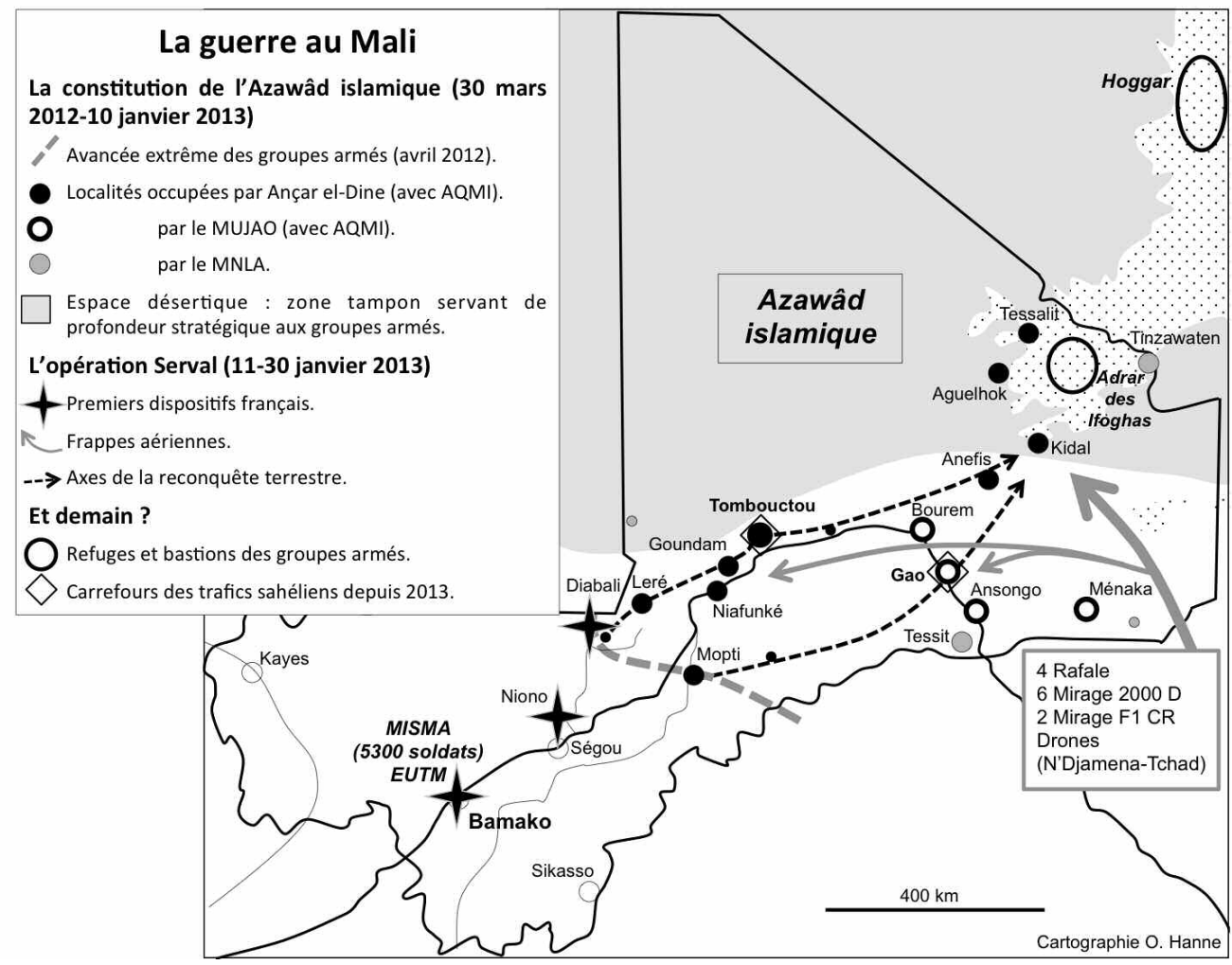

L'appel désespéré à la France du Président malien, Dioncounda Traoré, rencontre immédiatement le soutien de François Hollande et de l'opinion publique. L'ONU et la Chine sont hésitantes, la Russie et l'Iran radicalement hostiles. L'Algérie, elle, ne craint pas l'emploi de la force. Le 11 janvier, l'opération Serval est mise en branle. Elle est immédiatement relayée par des frappes aériennes et des commandos, renforcés en quelques jours par 4000 soldats français et 1500 véhicules, appuyés sur leurs arrières par les forces de la Misma (Mission internationale de soutien au Mali sous conduite africaine) et du Tchad, incapables d'assurer l'affrontement direct. Deux colonnes françaises remontent vers le nord-est à grande vitesse, dans des conditions logistiques extrêmes. Les premiers raids français touchent Gao et Tombouctou le 27 janvier, qui est libérée le lendemain. Les groupes armés s'enfuient vers Kidal et l'Adrar des Ifoghas où auront lieu les accrochages les plus violents, ainsi qu’à Gao, ville moins hostile que les autres aux insurgés. A partir du mois d'avril, l'ensemble du pays semble pacifié, ou du moins sous contrôle, l'immense espace désertique n'étant en réalité à personne, vaste zone tampon de circulation, de contrebande et de fuite. 


\section{Vers le chaos?}

Serval fut un succès militaire qui déboucha sur un début de règlement politique avec les accords de Ouagadougou entre le MNLA et les autorités de Bamako en mai 2013. Mais la poursuite des attentats au Nord-Mali et des opérations militaires européennes à travers le dispositif Barkhane (août 2014) prouve que rien n'a été réglé. L'avenir sahélien reste hypothéqué. Kidal est encore un bastion de l'islamisme exogène qui peut s'y reconstituer. Dans le Hoggar algérien et autour de Tamanrasset, des chefs djihadistes ont trouvé refuge. La prise d'otages d'Arlit (Niger) en octobre 2013 et la reconstitution des narco-trafics à Gao et Tombouctou sont des exemples bien concrets d'un danger toujours présent.

Aujourd'hui, la cohabitation entre chrétiens et musulmans, mais aussi entre Sahariens et Sahéliens, est partout menacée. En Centrafrique, les antagonismes ont explosé en raison des exactions de la Séléka, une milice de coupeurs de route, arabophones et musulmans. En prenant Bangui en avril 2013, la Séléka a déclenché l'intervention française, mais aussi une haine de la majorité chrétienne contre les musulmans du pays, étrangers aux pillages de la Séléka. Au Nord-Soudan, le salafisme d'État pousse à l'islamisation et au départ des chrétiens, qui peuvent se réfugier au Soudan du Sud, devenu indépendant en 2011 mais touché par une guerre civile.

Les prochaines zones menacées sont celles où cohabitent encore chrétiens et musulmans, et surtout celles où les djihadistes chassés sur Nord-Mali ont pu se réfugier : Tchad, Sud-Libye, Soudan occidental, Niger et Nigeria (où ils peuvent s'associer à Boko Haram). Enfin, le salafisme poursuivant sa diffusion grâce aux capitaux des monarchies du Golfe, on peut craindre dans quelques années pour la stabilité du Sénégal, de la Guinée et du Cameroun. La menace plane sur le Tchad, verrou de l'Afrique encerclé par les tensions libyennes, du Niger, de Boko Haram et du Soudan. La Libye, qui a basculé depuis 2013 dans le chaos, fait figure de principale plateforme du djihadisme africain, soutenu idéologiquement par l'État islamique en Irak et en Syrie. Depuis l'été 2014, la Cyrénaïque et la Tripolitaine sont devenues des émirats djihadistes.

Les interventions françaises du Mali, de Centrafrique et de Barkhane n'ont fait que ralentir la contagion. Si des opérations militaires ciblées comme Serval ou Sangaris ont leur utilité immédiate, elles ne peuvent apporter les profonds changements attendus dans l'économie et les systèmes politiques sahéliens, et encore moins contrer l'islamisation des sociétés africaines qui prépare leur ralliement conscient ou involontaire au djihadisme. Sur la route de la pacification, la France aurait besoin de toutes les forces militaires du continent, particulièrement de l'Algérie et du Maroc, mais ne pourra elle seule lancer les réformes qui sauveront les pays du Sahel. 